\title{
On the triggering of auroral substorms by northward turnings of the interplanetary magnetic field
}

\author{
J. A. Wild ${ }^{1}$, E. E. Woodfield ${ }^{1}$, and S. K. Morley ${ }^{2, *}$ \\ ${ }^{1}$ Department of Communication Systems, Lancaster University, Lancaster, LA1 4WA, UK \\ ${ }^{2}$ School of Mathematical and Physical Sciences, University of Newcastle, Callaghan, NSW 2308, Australia \\ *now at: Space Science and Applications, Los Alamos National Laboratory, Los Alamos, NM 87545, USA
}

Received: 23 September 2008 - Revised: 14 August 2009 - Accepted: 4 September 2009 - Published: 25 September 2009

\begin{abstract}
Some studies over the last decade have indicated that the instability responsible for substorm expansion phase onset may require an external trigger such as a northward turning of the interplanetary magnetic field (IMF). Statistical investigations have lead to contrasting interpretations regarding the relationship between proposed solar wind triggers and substorm onsets identified from geomagnetic data. We therefore present the results of a study into the possible triggering of 260 substorms between 2001-2005, exploiting data from the Cluster and IMAGE satellite missions. We find that only a small fraction $(<25 \%)$ of the substorms studied are associated with northward turnings of the IMF. However, the majority of the observed onsets are associated with a growth phase characterised using a subset of the criteria employed to define northward-turning IMF triggers. Based upon a case-by-case investigation and the results of an analysis using the statistics of point processes, we conclude that northward-turning structures in the IMF, while sometimes coinciding with the initial phase of individual substorms, are not required to trigger the magnetospheric instability associated with substorm expansion phase onset.
\end{abstract}

Keywords. Magnetospheric physics (Magnetospheric configuration and dynamics; Solar wind-magnetosphere interactions; Storms and substorms)

\section{Introduction}

Substorms represent one of the fundamental modes of global energy circulation and magnetic flux transport in the geospace environment (Cowley et al., 2003). Although on average the quantity of magnetic flux opened via dayside reconnection must be balanced by flux closure (occurring

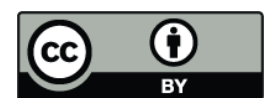

Correspondence to: J. A. Wild

(j.wild@lancaster.ac.uk) predominantly in the magnetotail), there is no requirement for the instantaneous flux opening and closure rates to be matched. Thus, in general, the balance between the dayside and nightside reconnection rates determines the amount of open magnetic flux within the magnetosphere (e.g. Lockwood and Morley, 2004). Following dayside reconnection, only a fraction of the flux transported into the tail is reconnected and convected back toward the dayside (Rostoker et al., 1987). The remaining flux is added to the tail lobes causing the magnetic flux density in the tail to increase. This stored energy is eventually released in an explosive fashion and the magnetosphere undergoes rapid reconfiguration. The processes of gradual energy storage followed by sudden release are usually referred to as the substorm growth and expansion phase, respectively.

Substorms therefore represent the explosive reconfiguration of the magnetosphere resulting from the release of solar wind energy and momentum stored in the Earth's magnetic tail. At the onset of the substorm expansion phase, an instability prompts the rapid reconfiguration of the magnetotail resulting in highly dynamic aurora and enhanced ionospheric currents. Since Akasofu first introduced the concept of substorms over 40 years ago (Akasofu, 1964), the mechanism and timing of the instability that leads to the rapid and large-scale reconfiguration of the Earth's magnetotail has been actively debated. Four decades of ground- and spacebased observations have led to the development of several models that rely upon different physical mechanisms to explain the sequence of cause and effect in the magnetosphere that result in the closure of open magnetic flux by reconnection in the tail and the auroral disturbances observed in the midnight sector auroral zones. The launch of NASA's Time History of Events and Macroscale Interactions during Substorms mission (THEMIS: Angelopoulos, 2008) in February 2007, has renewed scientific focus on the uncertainty in the location and timing of substorm expansion phase onset in the Earth's magnetic tail. Recent results from the mission (which

Published by Copernicus Publications on behalf of the European Geosciences Union. 
comprises five identically instrumented probes with orbits arranged such that during key observing seasons the spacecraft align radially every four days in order to measure the timing and evolution of the signatures of substorm onset) are dramatically advancing our understanding of the timing and location of substorm expansion phase onset (e.g. Angelopoulos et al., 2008).

Another key uncertainty is the possible triggering of substorm expansion phase onset by factors external to the magnetospheric cavity (rather than the spontaneous growth of a plasma instability in the magnetotail current sheet). In a study of upstream interplanetary conditions during $\sim 1800$ substorms, Caan et al. (1978) reported that the average $B_{Z}$ component of the interplanetary magnetic field (IMF) reached a negative peak approximately ten minutes prior to expansion phase onsets determined from ground magnetometer data. These findings led Caan and co-workers to speculate that northward turnings of the IMF may act as an onset trigger mechanism. Lyons et al. (1997) examined in situ solar wind and IMF measurements during substorm onsets and concluded that northward turnings of the IMF were responsible for triggering 13 of the 20 events studied. Lyons et al. (1997) went on to suggest that a large majority of substorms are triggered by the IMF, although the physical mechanisms linking the IMF structures to the growth of a magnetotail instability remain unclear. Subsequently, Hsu and McPherron (2002) searched for evidence of IMF triggers in 3 months of IMF data from the ISEE-2 spacecraft. Hsu and McPherron (2002) employed the same criteria as Lyons et al. (1997) in order to define a substorm trigger at time $t$ in a set of measurements of the north-south component $B_{Z}$ of the IMF sampled at discrete times $t_{i}$. Assuming time resolution $\Delta t=t_{i+1}-t_{i}=60 \mathrm{~s}$ in the solar wind measurements, these criteria are as follows:

1. The IMF must be southward for at least 22 of the preceding 30 min:

$\#\left\{B_{Z}(t-30 \Delta t: t)<0\right\} \geq 22$

where $X(a: b)$ denotes all elements of $X\left(x_{i}\right)$ in the range $a<x_{i} \leq b$ and $\#\{X\}$ indicates the number of elements in the set $X$.

2. The turning initiation must be rapid, so that:

$$
\frac{B_{Z}(t+\Delta t)-B_{Z}(t)}{\Delta t} \geq 0.375 \mathrm{nT} \mathrm{min}^{-1}
$$

3. The northward turning must be sustained, determined by the slope of the linear regression of $\nabla B_{Z}$ on $t_{i}$ between $t$ and $t+10 \mathrm{~min}$ :

$$
\frac{B_{Z}(t: t+10 \Delta t)}{10 \Delta t} \geq 0.175 \mathrm{nT} \mathrm{min}^{-1}
$$

and $B_{Z}$ must be increasing so as to satisfy the requirements $B_{Z}(t+\Delta t: t+3 \Delta t) \geq B_{Z}(t)+0.175 \mathrm{nT}$ and $B_{Z}(t+3 \Delta t: t+10 \Delta t) \geq B_{Z}(t)+0.45 \mathrm{nT}$.
4. No other point in the previous 10 min should satisfy the listed criteria. That is, once a trigger is identified, any turnings satisfying the criteria in the following $10 \mathrm{~min}$ interval are ignored.

Using the above criteria Hsu and McPherron (2002) examined 61731 1-min resolution data points from the ISEE-2 spacecraft while in the vicinity of 12:00 MLT and just upstream of the bow shock in September 1978 and SeptemberOctober 1979. Within these data, 598 possible substorm triggers were identified, while ground magnetometer measurements were employed to identify 258 substorm onsets within the same time range. The statistical association between triggers and onsets was then evaluated using the statistics of point processes, with the time delay between substorm onsets and the propagated arrival time of IMF triggers found to be clustered around zero. These results were interpreted as evidence that the association between northward turning triggers and substorm onsets is statistically significant at a confidence level so high that there is little possibility that the association is a result of chance.

However, in a re-analysis of the Hsu and McPherron (2002) dataset, Morley and Freeman (2007) demonstrated that the time delay between substorm onsets and the propagated arrival time of IMF triggers were also clustered around zero when only the first of the Lyons criteria listed above was employed. Morley and Freeman interpreted this result as evidence that given a period of southward IMF (corresponding to the substorm growth phase), northward IMF turning triggers (as described by criteria 2-4 of Lyons et al., 1997) were not required for a substorm expansion phase onset to occur.

Movement toward a resolution of the substorm triggering questions is often hampered by uncertainty in the configuration of the IMF and solar wind parameters controlling solar wind-magnetosphere-ionosphere coupling. Frequently, solar wind and IMF data recorded at the Sun-Earth L1 libration point are propagated Earthward in order to estimate the conditions impinging upon the magnetopause. However, significant errors can arise in the time delay estimation required to lag L1 data to the magnetosphere, making the one-toone association of IMF drivers with magnetospheric effects somewhat unreliable (e.g. Weimer et al., 2002). For example, measurements from the ACE spacecraft (Stone et al., 1998) are often employed. However, the $\sim 150000 \mathrm{~km}\left(\sim 23 R_{E}\right)$ semi-major axis of ACE's halo orbit about the L1 libration point implies that solar wind streamlines passing though the ACE spacecraft are unlikely to directly intersect the magnetopause. Therefore, in this study (as in the studies presented by Hsu and McPherron, 2002, and Morley and Freeman, 2007), we shall employ magnetic field and plasma data from a few $R_{E}$ sunward of the bow shock in order to minimise uncertainties in the propagation of upstream measurements to the magnetosphere for a large group of substorms. However, in contrast to Hsu and McPherron (2002) and Morley and Freeman (2007), we shall examine the upstream solar wind 
and IMF conditions during substorm onsets identified from space-based auroral imagery, rather than ground magnetometer measurements. By exploiting a different substorm onset identification method and comparing onset timings with solar wind and IMF measurements from the region just upstream of the bow shock, the results of the present investigation can be directly compared to the previous studies.

\section{Data analysis}

Upstream solar wind and IMF data for this study are taken from the European Space Agency's Cluster satellite mission (Escoubet et al., 1997, 2001). The quartet of Cluster spacecraft were launched in the summer of 2000 and orbit the Earth in highly elliptical polar orbits $\left(19 R_{E}\right.$ apogee/4 $R_{E}$ perigee) with periods of $\sim 57 \mathrm{~h}$. The orbits are fixed in inertial space such that the orbital plane precesses through $24 \mathrm{~h}$ of local time in 12 months. Between approximately January and April each year, this orbit configuration takes the spacecraft upstream of the bow shock as they pass through apogee. Measurements of the local magnetic field and plasma ion population at each Cluster spacecraft are provided by the fluxgate magnetometer (FGM; see Balogh et al., 1997, 2001) and the Cluster ion spectrometry (CIS; see Rème et al., 1997, 2001) experiments, respectively. After rejecting intervals during which there were more than $10 \mathrm{missing} / \mathrm{bad}$ data points in a given hour of spin-resolution $(\sim 4 \mathrm{~s})$ measurements, three component magnetic field data, ion density and ion velocity measurements have been averaged at 1-min resolution (as was the case in Lyons et al., 1997, and Hsu and McPherron, 2002).

In order to examine the relationship between upstream IMF conditions and substorm onsets, we require a list of candidate events. Frey et al. (2004) analysed auroral observations made by the IMAGE FUV instrument between May 2000 and December 2002, identifying 2437 individual substorms. Substorms were identified if they fulfilled the following criteria: (1) a clear local brightening of the aurora has to occur, (2) the aurora has to expand to the poleward boundary of the auroral oval and spread azimuthally in local time for at least $20 \mathrm{~min}$, (3) a substorm onset was only accepted as a separate event if at least $30 \mathrm{~min}$ had passed after the previous onset. The resulting list of events, subsequently extended to December 2005 to include a total of 4193 substorms (Frey, 2006), forms the basis of the present study. Of these events, we have identified 301 substorms that occurred when the Cluster 1 spacecraft was located upstream of the bow shock and making magnetic field and plasma measurements. After excluding candidate events that contained data gaps during two-hour intervals starting $90 \mathrm{~min}$ prior to the onsets listed by Frey and co-workers, the list of substorms to be examined is reduced to 260 individual events spanning the period 3 February 2001 to 1 May 2005. Figure 1 presents a summary of the locations of the Cluster 1 satellite during the 260 substorms examined in this study and investigated to identify possible IMF triggers.

Figure 2 presents upstream data during three example substorm onsets selected from the 260 events in our dataset. For each substorm onset, the location of the Cluster 1 spacecraft is compared to the model bow shock position as described by Roelof and Sibeck (1993). The model is parameterised according to average solar wind and IMF conditions observed by Cluster over a 2-h interval starting $90 \mathrm{~min}$ prior to onset. Based upon the position of the model bowshock, a solar wind propagation time $\left(T_{S W}\right)$ in the anti-sunward direction from the location of the spacecraft to the bowshock is calculated (typically $<1 \mathrm{~min}$ ). It is also necessary to take into account the propagation time of potential IMF trigger signals across the magnetosheath $\left(T_{S H}\right)$ and along magnetospheric field lines toward the Earth and magnetotail $\left(T_{M S}\right)$. The total propagation delay of IMF triggers $(T)$ is therefore estimated to be $T=T_{S W}+T_{S H}+T_{M S}$. In keeping with the analysis of Hsu and McPherron (2002), $T_{S H}$ and $T_{M S}$ are assumed to have fixed values of $4 \mathrm{~min}$ and $2 \mathrm{~min}$, respectively. The total propagation "lags" computed for each of the examples presented in Fig. 2 are shown in the right-hand frames. IMF $B_{Z}$ and solar wind dynamic pressure data are then lagged such that the presented time series correspond to the estimated arrival times of these structures in the magnetotail relative to the observed substorm onset time.

The uppermost pair of panels in Fig. 2 correspond to the substorm onset identified by Frey et al. (2004) at 07:50:43 UT on 8 February 2003. Following a southward turning $\sim 50 \mathrm{~min}$ prior to substorm onset, the $B_{Z}$ component of the IMF remained negative for the remainder of the interval while solar wind dynamic pressure was generally steady at $\sim 3 \mathrm{nPa}$ throughout. Times at which the first of the four Lyons triggering criteria (negative $B_{Z}$ for 22 out of the preceding $30 \mathrm{~min}$ ) is satisfied are indicated by yellow background shading (starting $44 \mathrm{~min}$ prior to onset). However, at no time during the interval presented were all four Lyons criteria satisfied.

The centre pair of panels in Fig. 2 correspond to the substorm onset at 17:26:28 UT on 18 March 2001. In this case, the IMF was generally southward in the 90 min preceding substorm onset. We note that the first Lyons criterion is satisfied from $t-61$ min to $t+12$ min while all four Lyons triggering criteria were satisfied $3 \mathrm{~min}$ after the onset time observed by IMAGE $(t+3 \mathrm{~min})$.

The final example presented in Fig. 2 (lower pair), corresponds to the onset at 10:21:32 UT on 2 February 2005. In this interval, the $B_{Z}$ component is variable, with several turnings of the IMF toward a more northward orientation. The first Lyons criterion is satisfied from $t-61 \mathrm{~min}$ to $t+2 \mathrm{~min}$ while all four Lyons triggering criteria were satisfied $3 \mathrm{~min}$ before the onset time observed by IMAGE $(t-3 \mathrm{~min})$. Although not considered by the Lyons triggering criteria, we note that at the time of the trigger there is also a modest 

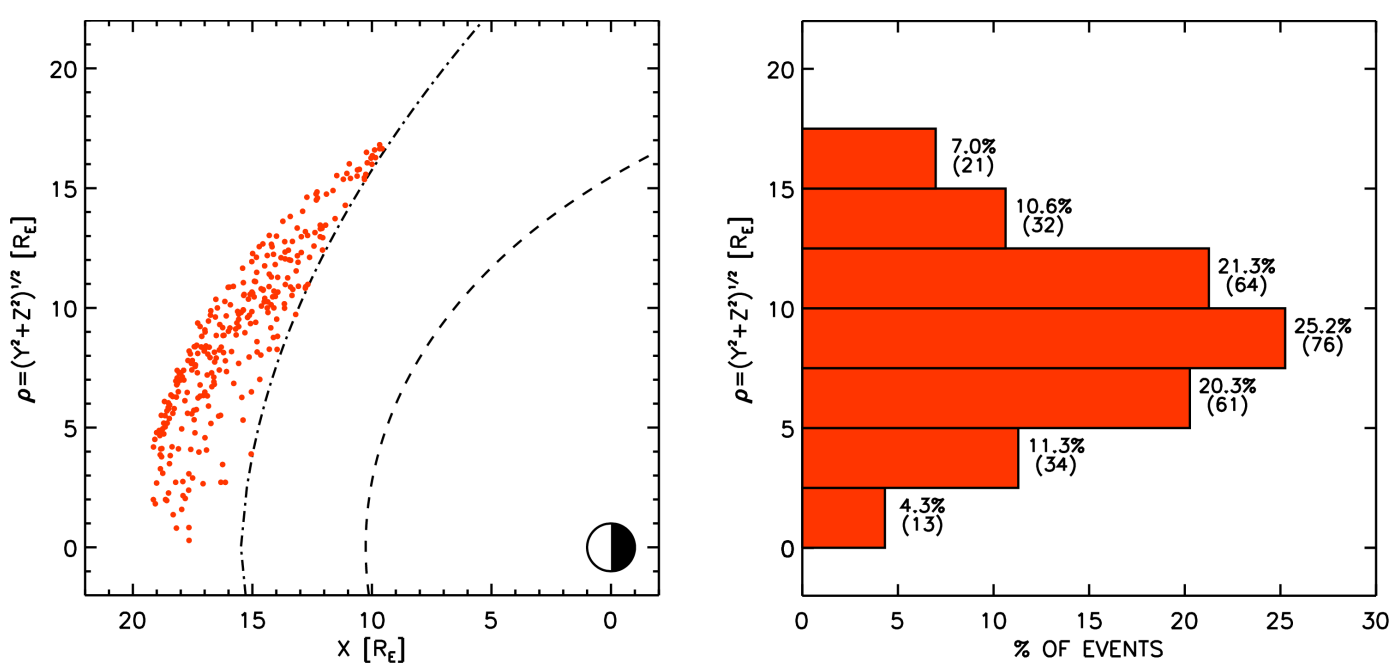

Fig. 1. The locations of the Cluster 1 spacecraft at the times of substorm onsets investigated in this study. The location of the spacecraft at the time of each onset is indicated as a dot in the left-hand panel, plotted according to its location in the GSM $X$ direction and $\rho=\left(Y^{2}+Z^{2}\right)^{1 / 2}$, the perpendicular distance from the Earth-Sun line. Model bow shock and magnetopause locations (after Roelof and Sibeck, 1993, and Shue et al., 1997) are included for reference and indicated by dash-dotted and dashed lines respectively. The right-hand panel shows the distribution of events as a function of $\rho$.

$(\sim 50 \%)$ and step-like increase in the solar wind dynamic pressure.

To summarise, according to the northward turning IMF trigger definition criteria used by Lyons et al. (1997) and Hsu and McPherron (2002), two of the three example events presented in Fig. 2 exhibit IMF triggers within a $\pm 10 \mathrm{~min}$ window centred on substorm onset (the window length used in the previous studies) while a third onset occurred without an accompanying IMF trigger. In the following section, we present the result of a study including all 260 events outlined above.

\section{Results}

Figure 3 presents an overview of the substorm triggering signatures observed in this study. For comparison, the same basic analysis has been repeated twice, once searching for IMF triggers that fulfil all four of the criteria set out by Lyons and co-workers (Fig. 3a) and once again looking for those times when only the first (southward IMF) criterion is satisfied (Fig. 3b). Beginning with Fig. 3a, the uppermost panel shows the distribution of triggers (satisfying all four of the Lyons criteria) observed within one minute wide bins over a \pm 10 min interval centred on substorm onset during all 260 onsets included in this study. For example, within the parent group of 260 onsets, Lyons type triggers were observed in the -10 min bin (i.e. within -10 to -9 min range) in two substorms. Likewise, Lyons type triggers were observed in the -1 min bin during five of the 260 onsets studied.
The lower three panels of Fig. 3a present equivalent distributions of Lyons triggers where, in each panel, the parent group of 260 substorm onsets is subdivided according to upstream solar wind and geomagnetic conditions. These data are presented in order to examine possible solar wind and geomagnetic factors that might influence the effectiveness of possible solar wind triggers. Specifically, these panels break down the Lyons type onsets into:

- Storm and non-storm time intervals (storm time intervals being defined at those with a $D_{s t}$ index less than $-40 \mathrm{nT})$

- Intervals of fast and slow speed solar wind flow (fast intervals being defined as those where the average solar wind speed exceeded $450 \mathrm{~km} / \mathrm{s}$ )

- Intervals with and without a solar wind dynamic pressure enhancement at the time of substorm onset (an enhancement being defined as a $>50 \%$ increase in dynamic pressure in the $20 \mathrm{~min}$ averaged window centred on substorm onset, compared to the preceding $20 \mathrm{~min}$ average)

Although the number of triggers in each bin is small, there is little evidence of a peak in the occurrence of Lyons-type triggers (satisfying all four criteria outlined above) in the few minutes either side of substorm onset. This is true of the parent dataset, as well as those subdivided according to solar wind and geomagnetic conditions. However, it is worthwhile noting that the majority of the observed triggers occurred during non-storm intervals with no evidence of solar 

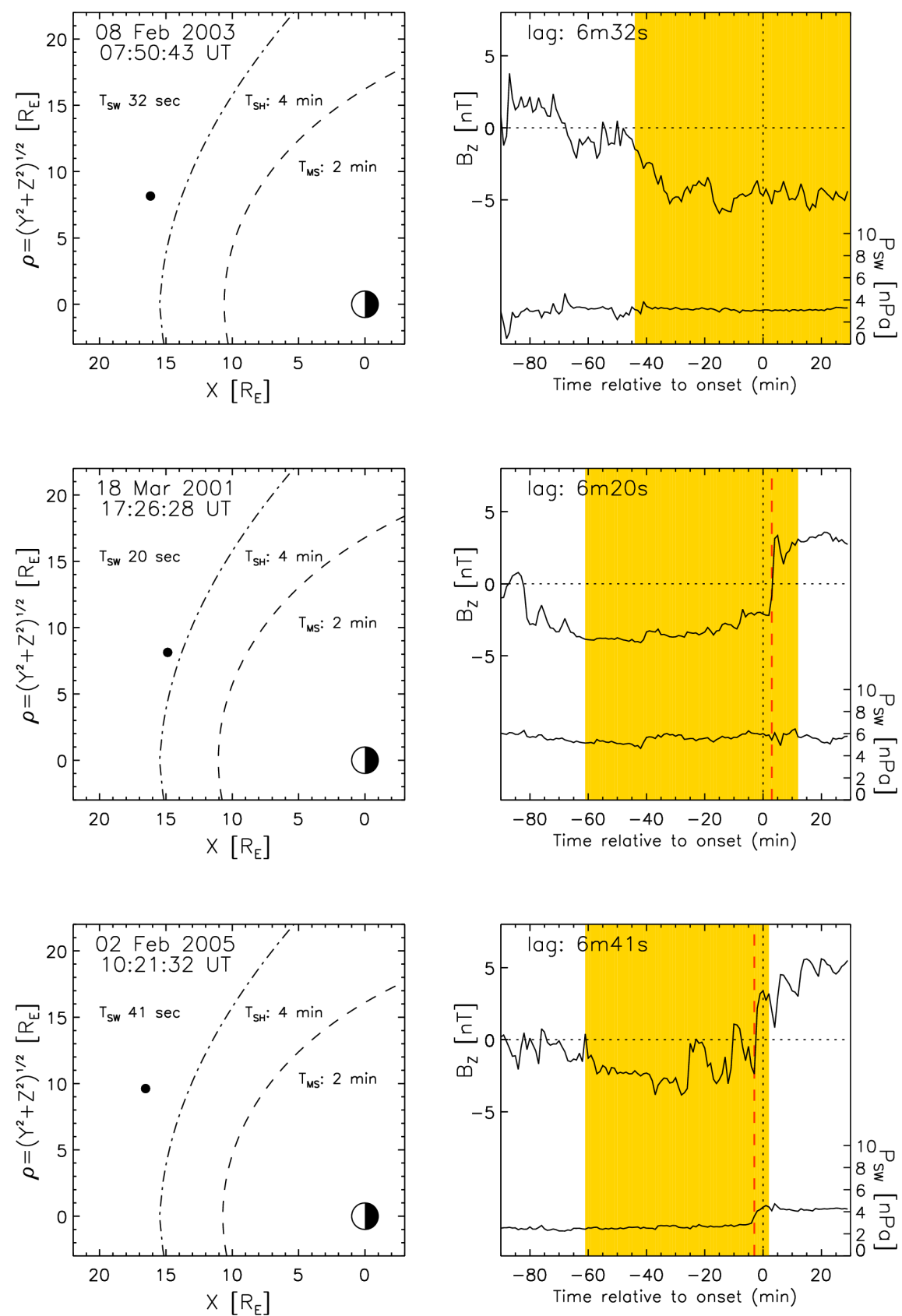

Fig. 2. Examples of IMF and solar wind conditions during 3 of the 260 substorm onsets investigated in this study. For each substorm, the left hand panel indicates the location of the Cluster 1 spacecraft relative to a model bow shock and magnetopause (as in Fig. 1). The right hand panels indicate the $B_{Z}$ component of the IMF and the solar wind dynamic pressure $\left(P_{S W}\right)$ as a function of time relative to substorm onset (with the time of onset shown by a vertical dotted line). Intervals during which the IMF conditions satisfy triggering criterion 1 of Lyons et al. (1997) are shaded yellow while instances where all 4 triggering criteria are satisfied are indicated by dashed red vertical lines. In the uppermost example, the criteria are not satisfied at any time and no dashed red line is included.

wind pressure enhancements, but the observed triggers were roughly evenly split between intervals of fast and slow solar wind speed.

Figure $3 \mathrm{~b}$ shows the equivalent distribution of instances when only the first Lyons criterion (22 min of southward IMF in the preceding $30 \mathrm{~min}$ ) is satisfied. The number of instances in each bin is significantly higher than in Fig. 3a (more than an order of magnitude) since the fourth Lyons criterion, specifying a $10 \mathrm{~min}$ period after each trigger during which subsequent triggers are ignored, is not included. However, the 
(a) Lyons IMF triggers

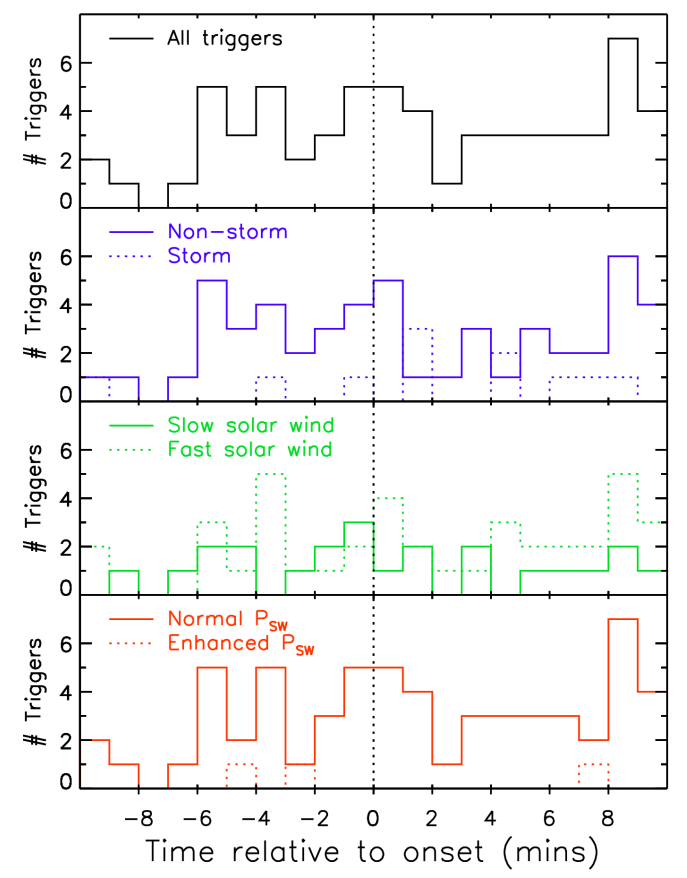

(b) Southward IMF triggers

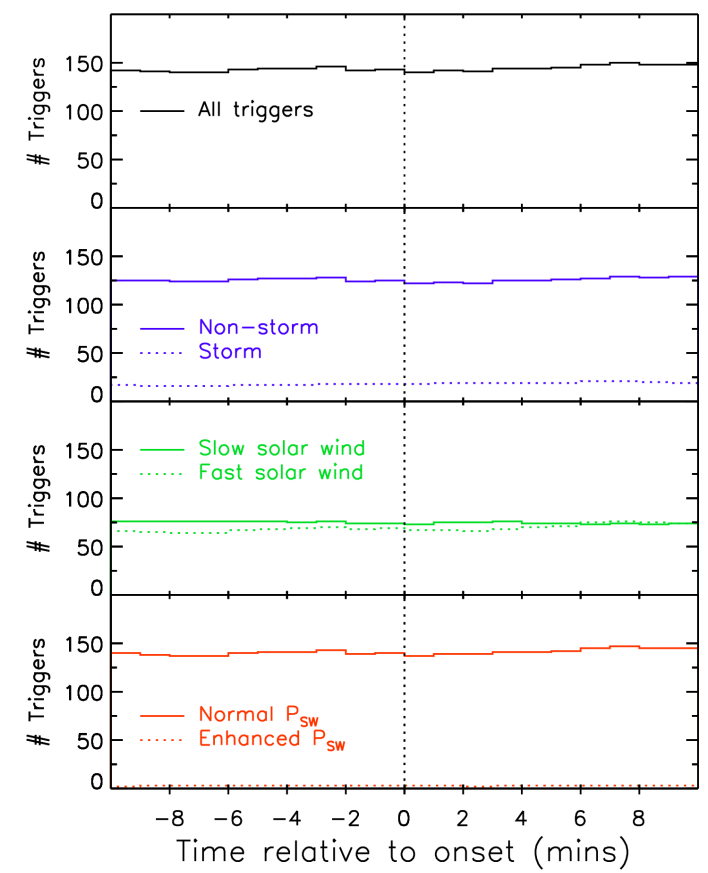

Fig. 3. The occurrence of substorm triggers within $\pm 10 \mathrm{~min}$ of substorm onset based upon (a) all four Lyons et al. (1997) criteria and (b) triggers satisfying only the first (southward IMF) criterion. In both cases, the panels present (from top to bottom) the occurrence within the parent distribution of all substorm onsets; occurrence during storm and non-storm intervals; occurrence during intervals of fast and slow solar wind; occurrence during intervals with changes in solar wind dynamic pressure (as described in the text).

distribution of instances where the southward IMF criterion is satisfied is broadly uniform across the $\pm 10 \mathrm{~min}$ period either side of the observed substorm onsets, regardless of solar wind and geomagnetic conditions. The sizeable increase in the fraction of onsets associated with extended intervals of southward IMF (Lyons criterion 1) compared to northwardturning IMF triggers (Lyons criteria 1-4), regardless of association window, suggests that southward IMF is a more significant factor in the development of a substorm expansion phase onset.

Figure 4 presents a superposed epoch analysis of upstream IMF $B_{Z}$ measurements for all 260 onsets included in this study. Specifically, Fig. 4a presents the variation in the median IMF $B_{Z}$ (lagged to the Earth) spanning the two hour interval starting $90 \mathrm{~min}$ prior to substorm onset while Fig. $4 \mathrm{~b}$ presents the variation in the mean IMF $B_{Z}$ (also lagged to the Earth) spanning a longer eight hour interval, centred on substorm onset (equivalent to Fig. 4 of Caan et al. (1978)). These data indicate that the onsets are typically preceded by $\sim 1 \mathrm{~h}$ of southward IMF, with the maximum southward IMF occurring $\sim 10-20 \mathrm{~min}$ prior to zero epoch time.

In their statistical analysis of 258 substorms onsets, Hsu and McPherron (2002) reported that $\sim 10$ min was the optimal half-width of the association window between substorm onsets and triggering signatures observed in the solar wind (when time-lagged as above). Therefore, in Fig. 5 we present the number of substorms where an IMF trigger was observed, for varying window sizes. In the case of northward turning IMF triggers (as defined by Lyons criteria 1-4) between 14 and 61 of the 260 substorms examined were associated with an IMF trigger in association windows ranging from \pm 1 to \pm 10 min of substorm onset, respectively. When the definition was relaxed to include only the southward IMF criterion (Lyons criterion 1), the number of substorms associated with IMF control increased to between 146 and 183 events for association windows ranging from \pm 1 to \pm 10 min of substorm onset, respectively.

\section{Discussion}

For the 260 substorm onsets examined in this study, the IMF propagation time from the Cluster 1 spacecraft to Earth, including the magnetosheath and magnetospheric transit times employed by Lyons et al. (1997), Hsu and McPherron (2002) and Morley and Freeman (2007), varied between between 6$8 \mathrm{~min}$. Given that these propagation delays (and their expected uncertainties) are comparable to the \pm 10 min window employed by previous studies in order to associate trigger signatures with substorm onsets, we would expect any systematic IMF triggering effect to be clearly apparent. 

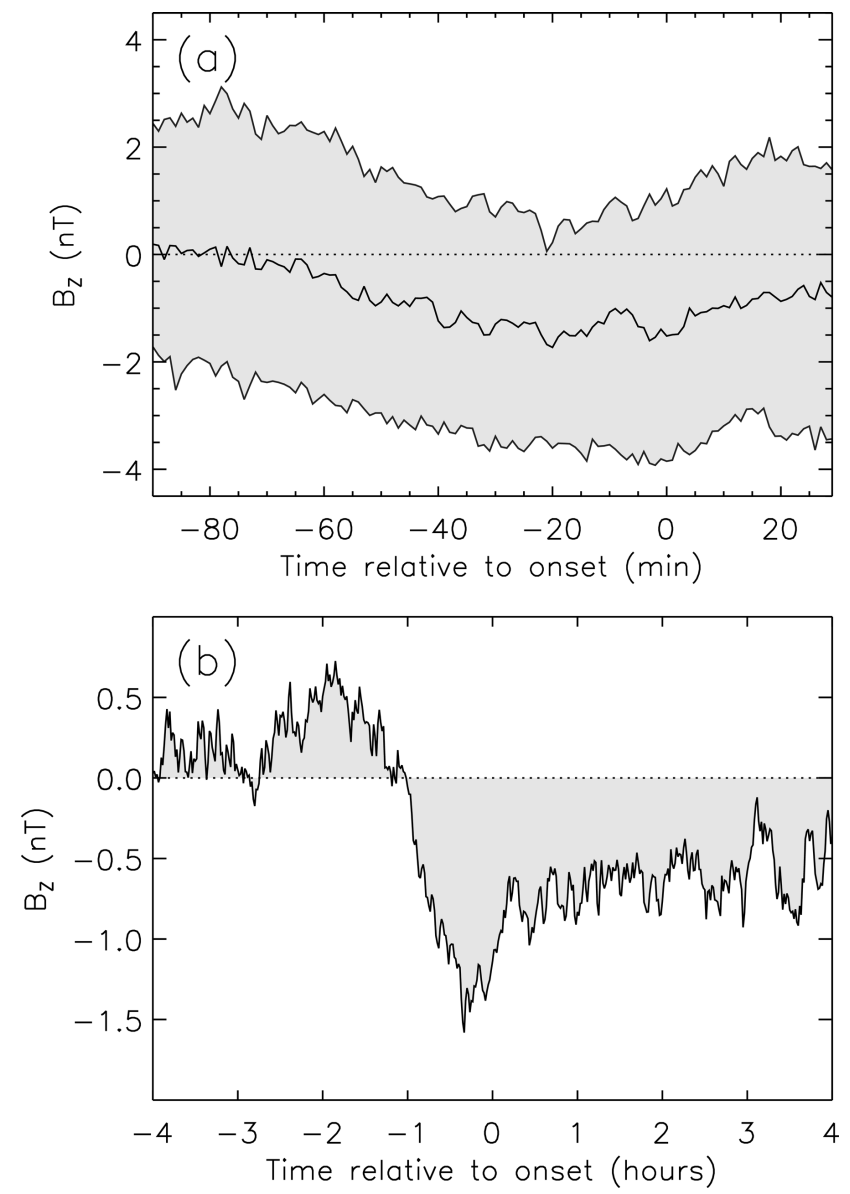

Fig. 4. (a) Median IMF $B_{Z}$ values (black trace) spanning the two hour interval starting $90 \mathrm{~min}$ prior to substorm onset for the 260 events included in this study. The range of values defined by the upper and lower quartiles is indicated by the shaded region. (b) Mean IMF $B_{Z}$ values spanning the eight hour interval centred on substorm onset for the 260 events included in this study.

Although broadly split between intervals of fast and slow solar wind speed, the vast majority of the substorm onsets included in this study occurred during non-storm times and were not associated with step-like increases in solar wind dynamic pressure (as indicated in Fig. 3).

The analysis summarised in Fig. 5 indicates that northward-turning IMF triggers satisfying Lyons criteria 14 are associated with less than a quarter of the substorms examined, even when a \pm 10 min association window is employed. If the association window size is reduced to $\pm 4 \mathrm{~min}$ (comparable to the typical estimated Cluster-Earth propagation time of $\sim 7 \mathrm{~min}$ ), the number of substorms associated with northward-turning IMF triggers falls to under $12 \%$. This relation between the fraction of substorms associated with northward-turning IMF triggers and the length of the association window is confirmed by the broadly uniform distribution of triggers relative to substorm onset (Fig. 3a).
If the upstream IMF conditions are relaxed to only include the first Lyons criterion, then the "triggering" is simply an indication of $>22 \mathrm{~min}$ of southward IMF in the preceding 30 min, i.e. a simple definition of the southward IMF conditions that might be expected during the substorm growth phase. As indicated in Fig. 3b, this simple southward IMF growth phase criterion is satisfied with almost uniform probability at various times in the \pm 10 min window either side of substorm onset. When comparing the fraction of onsets associated with this growth phase criteria, the percentage grows from $56 \%$ for a $\pm 1 \mathrm{~min}$ association window to over $70 \%$ for a \pm 10 min window. Although the fraction of onsets satisfying the growth phase criterion is much greater then those satisfying all four Lyons criteria (regardless of association window size), a significant fraction of onsets remain unaccounted for. We suggest that this is an indication that the first Lyons criterion fails to adequately describe the substorm growth phase. For example, evidence suggests that open flux continues to be added to the terrestrial magnetosphere via dayside reconnection even under positive IMF $B_{Z}$ conditions as long as the IMF clock angle, defined as $\arctan \left(B_{Y} / B_{Z}\right)$, exceeds $45^{\circ}$ (Sandholt et al., 1998). We note that if the growth phase criterion is redefined to find times when the modulus of the IMF clock angle was greater than $45^{\circ}$ for at least 22 of the preceding $30 \mathrm{~min}$, the percentage of onsets satisfying the criterion increase to between $89 \%-93 \%$ for 1-10 min association windows, respectively (as shown in Fig. 5).

The high likelihood of a period of southward IMF prior to the onsets included in this study is further highlighted in Fig. 4. The median upstream $B_{Z}$ values (Fig. 4a) indicate that the IMF is typically southward during the hour prior to substorm onset (i.e. during the expected substorm growth phase). When considered over a longer time interval, the mean upstream $B_{Z}$ values (Fig. $4 \mathrm{~b}$ ) are similar to the upstream IMF conditions presented during separated substorms by Caan et al. (1978). The IMF component is small and slightly positive four hours prior to onset before turning southward for the majority of the intervals presented, reaching a maximum negative of $-1.58 \mathrm{nT}$ twenty minutes prior to substorm onset (compared of a maximum negative of around $-2.25 \mathrm{nT}$ about twenty minutes prior to substorm onset reported by Caan et al. (1978)). Apart from brief southward excursions at $t-170$ and $t-71 \mathrm{~min}$, the mean IMF $B_{Z}$ only becomes negative $60 \mathrm{~min}$ prior to substorm onset. This is somewhat different to the trend shown by Caan et al. (1978), who reported that the mean IMF for separated substorms turned southward $\sim 150 \mathrm{~min}$ prior to onset. However, in both cases, the amplitude of the IMF $B_{Z}$ component (regardless of sign) is found to be less than one third of the maximum amplitude until about one hour prior to zero epoch.

Based on Fig. 4, there is an obvious tendency for the IMF to be southward prior to substorm onset and then to turn northward around the time of zero epoch. Indeed, this has previously been cited as evidence for the triggering of substorms by northward turnings of the IMF (e.g. Samson and 


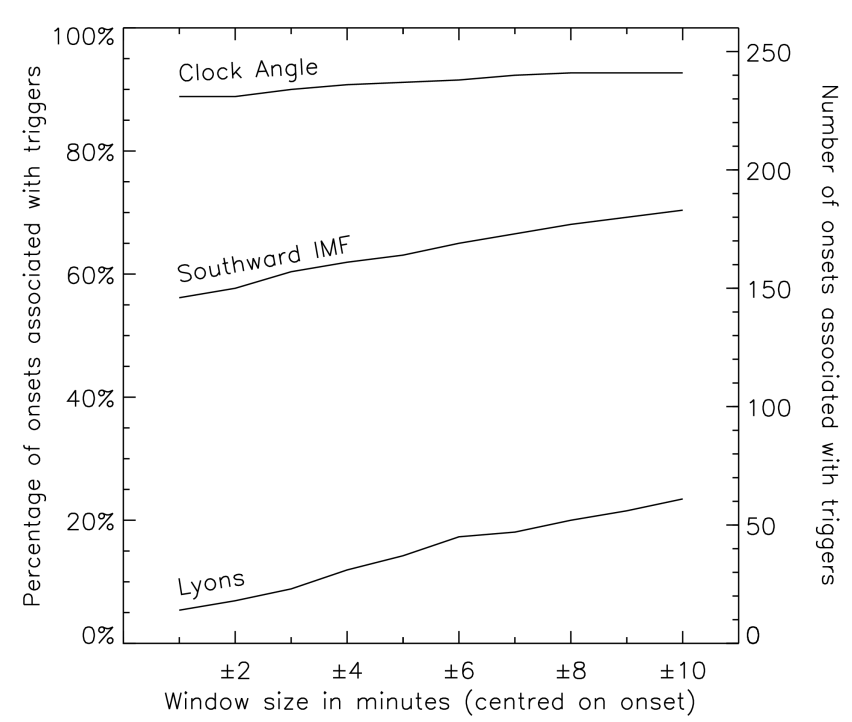

Fig. 5. Variations in the number of substorms associated with IMF triggers as a function of association window length. The number of substorms with at least one trigger within the indicated window length is presented for both northward IMF triggers (according to Lyons criteria 1-4), southward IMF triggers (Lyons criterion 1 only) and the IMF clock angle criterion introduced in the text (more than 22 min of IMF clock angle magnitude greater than $45^{\circ}$ in the preceding $30 \mathrm{~min}$ ).

Yeung, 1986). However, since substorm onsets are biased to occur during intervals of southward IMF and the long-term distribution of IMF $B_{Z}$ values has a mode of $0 \mathrm{nT}$, it is reasonable to expect that from a highly negative point on the IMF $B_{Z}$ distribution changes will, on average, tend towards zero (i.e. in the positive direction). Therefore, although consistent with the data of Caan et al. (1978), we cannot interpret the results presented in Fig. 4 as evidence of a causal link between northward turnings of the IMF and substorm onsets.

In order to examine any possible causal link more rigourously, an analyses of trigger signatures has been undertaken based on the statistics of point processes (e.g. Cox, 1955; Brillinger, 1976). This test has previously been applied to substorm onsets and their candidate triggers by Hsu and McPherron (2002) and Morley and Freeman (2007). The reader is directed to these papers for a comprehensive description of the technique but, as described in Morley and Freeman (2007), the association between two point processes is assessed using the association number, calculated as follows. Given two point process (i.e. time series of discrete events) $A$ and $B$, with events at times $a_{i}(i \in\{1,2, \ldots N\})$ and $b_{j}+u(j \in\{1,2, \ldots M\})$, respectively, where $u$ is a time lag. The individual association number $c_{i}$ is the number of events in series $B$ that fall into a window of half-width $h$ around $a_{i}$ and the association number $n(u, h)$ is the summation of $c_{i}$ over all events $a_{i}$ $n(u, h)=\sum_{i=1}^{N} c_{i}=\sum_{i=1}^{N} \#\left\{\left|b_{j}+u-a_{i}\right|<h\right\}$

where \#\{X\} denotes the number of elements in the set $X$. For independent processes, the association number is wellestimated by the asymptotic association number $n(u \rightarrow \infty, h)$ since separating any two time series by sufficient time will ensure independence between the points in the two series. Therefore, if there is no association between point processes $A$ and $B$ for any lag $u$, there will be no significant departure from its asymptotic value at any lag. Alternatively, if there is an association between point processes $A$ and $B$, a significant departure from the asymptotic level is expected at some lag. In the case of the IMF $B_{Z}$ triggering hypothesis, we would expect the departure from the asymptotic level at a lag relatively close to zero. A bootstrapping technique (Conover, 1999 ) is employed in order to evaluate the sampling variation in $n(u, h)$ and establish the $95 \%$ confidence limits for the sampling variation (after Morley and Freeman, 2007).

Figure 6 presents the association number analysis of candidate IMF "triggers" within a window of $\pm h$ of observed onset times, as a function of lag $u$. For this analysis, the window was set to a half-width of $h=10 \mathrm{~min}$ in order to give results comparable with Hsu and McPherron (2002) and Morley and Freeman (2007). In the first instance we assess the association between northward turning IMF triggers as defined by Lyons criteria 1-4 applied to Cluster 1 magnetic field data whenever the spacecraft was located within the solar wind between February 2001 and December 2005. For comparison, all 3494 substorm onset timings identified in Frey et al. (2004) over the same period are compared. By doing so, we include all triggers observed when Cluster was in the solar wind (regardless of whether or not an onset was observed) and all onsets observed by IMAGE (whether or not upstream IMF data were available). Figure 6 a shows the association number between these point processes as a function of lag $u$, summed over all onset times. In order to aid the comparison between this and subsequent panels, the left-hand axis is normalised to the relevant asymptotic association number, while the actual association number are marked on the righthand axis. In all, we have $N=3494$ onsets and $M=1323$ triggers. At lags of $|u|>200$ min the association number tends to a mean asymptotic association number of 39 . The peak in normalised association is $n(u, h)=1.88$ (with $95 \%$ confidence limits of 1.45-2.37) at $u=-6 \mathrm{~min}$. The lower confidence interval is above the asymptotic association number for $-22<u<10 \mathrm{~min}$.

The analysis is repeated, substituting Lyons $B_{Z}$ triggers for instances when only Lyons criterion 1 is satisfied, i.e. substituting northward turning triggers for instances where $>22$ min of southward IMF are observed in the preceding $30 \mathrm{~min}$ (referred to as "internal triggers" by Morley and Freeman, 2007). The results are presented in Fig. 6b, with the results from Fig. 6a shown for comparison. In all, we have $N=3494$ onsets and $M=63505$ internal triggers. 

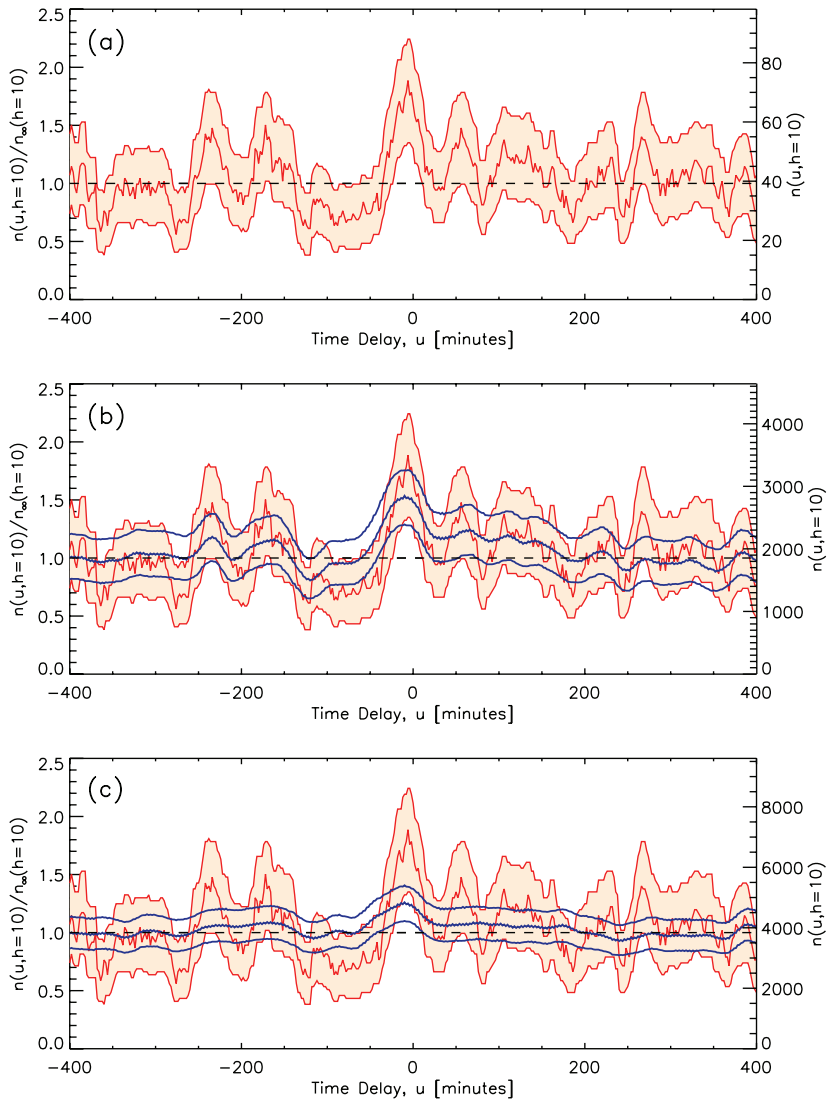

Fig. 6. (a) Association number (thick red line) of candidate external triggers defined by Lyons criteria 1-4 within a window of $\pm h$ of the onset time (summed over all observed onsets) as a function of the lag $u$. The association number $n(u, h)$ is marked on the right-hand axis and normalised to the asymptotic association number on the left hand axis. The thin red lines containing the shaded region mark the $95 \%$ confidence limits and the dashed horizontal line indicates the expected association under independence. (b) The association number (thick blue line) of candidate internal triggers defined by Lyons criterion 1 only. The $95 \%$ confidence limits are indicated by the upper and lower blue lines and the results from panel (a) are repeated for comparison and scaled according to the left-hand axis. (c) Same as panel (b), but for observed substorms onsets and instances where the $>45^{\circ}$ clock angle criterion described in the text is satisfied.

At lags of $|u|>200$ min the association number tends to a mean asymptotic association number of 1856 . The peak in normalised association is $n(u, h)=1.54$ (with 95\% confidence limits of 1.3-1.78) at $u=-10 \mathrm{~min}$. The lower confidence interval is above the asymptotic association number for $-42<u<20 \mathrm{~min}$.

The analysis is repeated for a third time, substituting Lyons $B_{Z}$ triggers for instances when $>22$ min of IMF clock angle magnitude $>45^{\circ}$ are observed in the preceding $30 \mathrm{~min}$. The results are presented in Fig. 6c, again with the results from Fig. 6a shown for comparison. In all, we have $N=3494$ onsets and $M=133429$ instances where the clock angle criterion is met. At lags of $|u|>200 \mathrm{~min}$ the association number tends to a mean asymptotic association number of 3840 . The peak in normalised association is $n(u, h)=1.26$ (with $95 \%$ confidence limits of 1.11-1.42) at $u=-10 \mathrm{~min}$. The lower confidence interval is above the asymptotic association number for $-42<u<10 \mathrm{~min}$.

Considering the analysis presented in each panel of Fig. 6 , if the association between substorm onsets and the relevant IMF criterion is no greater than that expected by chance, then the association number should be similar at all lags. However, this is not the case here. In each panel of Fig. 6, there are significant deviations from the expected association under independence. As such, the results indicate that (a) northward IMF triggers, as defined by Lyons criteria 1-4, (b) intervals of southward IMF, as defined by Lyons criteria 1 and (c) intervals of IMF with clock angle magnitude $>45^{\circ}$ are all associated with substorm onsets. The maximisation of association at lags just prior to onset is due to the need to propagate the solar wind such that the measured flux is added into the magnetospheric lobe. Examining Fig. 6b, the 95\% confidence limits of the Lyons criteria 1-4 criteria (indicated by the red shaded region) encompass both the calculated association number for Lyons criterion 1 and a significant fraction of the confidence limits for Lyons criterion (indicated by the blue traces). Indeed, the confidence limits on the estimate of the association number for Lyons criteria 1-4 overlaps the calculated association number for Lyons criterion 1 and $\sim 70 \%$ of the confidence interval around it. This substantial overlap suggests that the primary factor in the association of "triggers" with onsets (described by Lyons criteria 1-4) is the inclusion of the southward IMF criterion (Lyons criterion 1). The results are similar to those of Morley and Freeman (2007), despite being based upon upstream IMF data from different spacecraft and relying upon very different onset identification techniques.

The association of onsets with clock angle (Fig. 6c) is statistically significant, but the substantially lower normalised association number indicates that it is a worse predictor of onset than either of the other two criteria. On first inspection, this seems at odds with results above showing the high percentage of onsets following $>22$ min of IMF clock angle magnitude $>45^{\circ}$ in the preceding $30 \mathrm{~min}$ (as indicated in Fig. 5). However, given that the association number analysis is applied to more substorm onsets, the results indicate that the clock angle criterion is fulfilled for a large number of nonsubstorm intervals. In other words, while large numbers of onsets are preceded by more than $22 \mathrm{~min}$ of IMF with a clock angle larger than $45^{\circ}$ (either positive or negative) within a half hour period, many such periods of this IMF orientation are not followed by a substorm.

Our analysis therefore suggests that even though the clock angle criterion fits a large fraction of events, it is too broad a descriptor and further study is required to better understand both the necessary and sufficient conditions for onset. 
Combined with the distribution of the temporal distribution of triggers before and after onset (as indicated in Fig. 3), we interpret the results of this study as evidence that northward turnings of the IMF are not required to trigger substorm onsets and conclude that the association between northward turnings and substorm onsets arises from the fact that northward turnings are biased to occur under southward IMF, as reported in Morley and Freeman (2007).

\section{Summary and conclusions}

In this study we have analysed upstream solar wind measurements during 260 substorm onsets in order to investigate the significance of northward-turning IMF triggers, of the kind proposed by Lyons et al. (1997). The substorm onset times are derived from IMAGE FUV observations of the UV aurora (as described by Frey et al., 2004) and are based upon a clear local brightening of the aurora, the poleward and azimuthal expansion of the auroral oval and $30 \mathrm{~min}$ temporal separation from the previous onset. In this respect, the substorms studied are similar to the "classical" substorms defined by Lyons et al. (1997). Simultaneous solar wind and IMF measurements are drawn from the Cluster 1 satellite in the region immediately upstream $\left(<5 R_{E}\right)$ of the bowshock and within $17 R_{E}$ of the Earth-Sun line. By exploiting such near-Earth measurements, the propagation time (and associated errors) of observed IMF structures to the Earth is minimised.

Based upon a case-by-case examination of these substorm onsets, we suggest that there is no requirement for a northward-turning IMF trigger of the kind proposed by Lyons et al. (1997), to initiate expansion phase onset. If, for example, we consider the northward-turning IMF trigger signatures observed with \pm 10 min of substorm onsets - an association window more than twice the length of the typical upstream propagation delay from Cluster to the Earth - less than a quarter of the onsets studied indicate any evidence of triggering. Conversely, greater than $70 \%$ of the observed onsets occur following an interval of southward IMF characterised by $>22 \mathrm{~min}$ in the preceding half-hour. The overarching trend, with only a minority of substorm onsets being associated with a northward-turning IMF trigger, appears unaffected by the prevailing solar wind speed and geomagnetic storm activity. Of the 260 onsets studies, only a handful were associated with solar wind dynamic pressure pulses. As such, there is insufficient statistical evidence to comment upon possible onset triggers due to changes solar wind dynamic pressure.

The majority of substorms studied follow an interval of southward IMF satisfying the first of the four Lyons criteria used to define northward-turning IMF triggers. Indeed, the average IMF conditions during the substorm growth phase and onset are very similar to those reported by Caan et al. (1978). However, the number of onsets observed that failed to satisfy the first Lyons criterion (approximately 30\% of those studied) suggests that the southward IMF growth phase description encapsulated by $>22 \mathrm{~min}$ of negative $B_{Z}$ in the preceding half-hour does not fully describe the IMF drivers corresponding to the substorm growth phase. A modified growth phase criterion, based upon the IMF clock angle instead of the north-south component of the IMF alone, is found to account for over $90 \%$ of the onsets included in our case-by-case investigation.

An analysis based upon the statistics of point processes has been used to investigate the association between substorm onsets and both northward IMF triggers (Lyons criteria 1-4) and southward IMF intervals (Lyons criterion 1). In both cases, the associations are statistically significant $(>95 \%$ confidence), suggesting that the primary factor in the association of "triggers" with onsets is the inclusion of the southward IMF criterion. The same analysis suggested that although a statistically significant association existed between the proposed clock angle criterion and substorm onsets, the criterion is too broad to reliably predict the timing of substorm onsets from upstream IMF measurements.

In summary, our findings relate to earlier studies as follows:

- The average observed IMF $B_{Z}$ component was southward in the hour prior to substorm onset, reaching a maximum negative amplitude approximately $20 \mathrm{~min}$ prior to substorm onset. This result is consistent with that of Caan et al. (1978). In both studies, the amplitude of the IMF $B_{Z}$ component (regardless of sign) is found to be less than one third of the maximum amplitude until about one hour prior to zero epoch. Since substorm onsets are biased to occur during intervals of southward IMF, it is reasonable to expect that from a highly negative point on the IMF $B_{Z}$ distribution changes will, on average, tend in the positive direction. Therefore, we do not interpret the results of the current study as evidence of a causal link between northward turnings of the IMF and substorm onsets.

- In a case-by-case analysis of the events included in our study, we find a number of substorms that follow northward IMF triggers as defined by Lyons et al. (1997). However, these "triggered" onsets account for less than a quarter of the onsets observed. The evidence presented here is therefore inconsistent with the conclusion of Lyons et al. (1997) that "a large majority of classical substorms are triggered by the IMF".

- Studies by Hsu and McPherron (2002) and Morley and Freeman (2007) have both exploited the statistics of point processes in order to study the significance of any association between the northward-turning IMF triggers described by Lyons et al. (1997) and substorm onsets. In Hsu and McPherron (2002), a significant statistical association was demonstrated, but the Morley and Freeman (2007) study, re-analysing the same dataset, 
showed that the same association was still present when only a subset of the triggering criteria were used, specifically the requirement for $>22 \mathrm{~min}$ of negative $B_{Z}$ in the half-hour preceding substorm onset. Using an entirely independent database of upstream IMF data and onset timings, the results of an identical analysis in the current study suggest that the primary factor in the association of "triggers" with onsets is the inclusion of the southward IMF criterion, consistent with the conclusions of Morley and Freeman (2007).

The results of the current study indicate that northwardturning IMF triggers are not required for expansion phase onset, even if such features are sometimes observed at the time of onset. We therefore conclude that the association between northward turnings and substorm onsets arises from the fact that northward turnings are biased to occur under southward IMF.

Acknowledgements. Cluster data employed in this study were downloaded from the Cluster Active Archive (http://caa.estec.esa. int/). The authors thank E. Lucek and H. Rème, PIs of the Cluster FGM and CIS experiments respectively, for the provision of data. The authors are grateful to $\mathrm{H}$. U. Frey for making the list of substorms available to the community and are indebted to M. P. Freeman for helpful discussions during the preparation of this paper. JAW and EEW are supported by STFC (formerly PPARC) grant number PP/E001947/1. SKM was partly supported by by ARC Discovery Project DP0663643.

Topical Editor R. Nakamura thanks G. Abel and another anonymous referee for their help in evaluating this paper.

\section{References}

Akasofu, S. I.: The development of the auroral substorm, Planet. Space Sci., 12, 273-282, 1964.

Angelopoulos, V.: The THEMIS mission, Space Sci. Rev., 141, 524, doi:10.1007/s11214-008-9336-1, 2008.

Angelopoulos, V., McFadden, J. P., Larson, D., Carlson, C. W., Mende, S. B., Frey, H., Phan, T., Sibeck, D. G., Glassmeier, K.H., Auster, U., Donovan, E., Mann, I. R., Rae, I. J., Russell, C. T., Runov, A., Zhou, X.-Z., and Kepko, L.: Tail Reconnection Triggering Substorm Onset, Science, 321(5891), 931-935, doi:10.1126/science.1160495, 2008.

Balogh, A., Dunlop, M. W., Cowley, S. W. H., Southwood, D. J., Thomlinson, J. G., Glassmeier, K.-H., Musmann, G., Lhr, H., Buchert, S., Acua, M. H., Fairfield, D. H., Slavin, J. A., Riedler, W., Schwingenschuh, K., and Kivelson, M. G.: The Cluster magnetic fields investigation, Space Sci. Rev., 79, 65-91, 1997.

Balogh, A., Carr, C. M., Acuña, M. H., Dunlop, M. W., Beek, T. J., Brown, P., Fornacon, K.-H., Georgescu, E., Glassmeier, K.H., Harris, J., Musmann, G., Oddy, T., and Schwingenschuh, K.: The Cluster Magnetic Field Investigation: overview of in-flight performance and initial results, Ann. Geophys., 19, 1207-1217, 2001,

http://www.ann-geophys.net/19/1207/2001/.

Brillinger, D. R.: Measuring the association of point processes: A case history, Am. Math. Mon., 83, 16-22, 1976.
Caan, M. N., McPherron, R. L., and Russell, C. T.: The statistical magnetic signature of magnetospheric substorms, Planet. Space Sci., 26, 269-279, 1978.

Conover, W. J.: Practical Nonparametric Statistics, John Wiley, Hoboken, N. J., third edn., 1999.

Cowley, S. W. H., Davies, J. A., Grocott, A., Khan, H., Lester, M., McWilliams, K. A., Provan, G., Sandholt, P. E., Wild, J. A., and Yeoman, T. K.: Solar wind-magnetosphere-ionosphere interactions in the Earth's plasma environment, Phil. Trans. A., 361, 113-126, 2003.

Cox, D. R.: Some statistical methods connected with series of events, J. R. Stat. Soc., Ser. B, 17, 129-164, 1955.

Escoubet, C. P., Schmidt, R., and Goldstein, M. L.: Cluster - science and mission overview, Space Sci. Rev., 79, 391-391, 1997.

Escoubet, C. P., Fehringer, M., and Goldstein, M.: The Cluster mission, Ann. Geophys., 19, 1197-1200, 2001, http://www.ann-geophys.net/19/1197/2001/.

Frey, H. U.: Substorm onsets as observed by IMAGE-FUV, Substorms VIII, Proceedings of the 8th International Conference on Substorms, Banff, 26-31 March 2006, pp. 71-75, 2006.

Frey, H. U., Mende, S. B., and Angelopoulos, V.: Substorm onset observations by IMAGE-FUV, J. Geophys. Res., 109, A10304, doi:10.1029/2004JA010607, 2004.

Hsu, T.-S. and McPherron, R. L.: An evaluation of the statistical significance of the association between northward turnings of the interplanetary magnetic field and substorm expansion onsets, J. Geophys. Res., 107, 1398, doi:10.1029/2000JA000125, 2002.

Lockwood, M. and Morley, S. K.: A numerical model of the ionospheric signatures of time-varying magneticreconnection: I. ionospheric convection, Ann. Geophys., 22, 73-91, 2004, http://www.ann-geophys.net/22/73/2004/.

Lyons, L. R., Blanchard, G. T., Samson, J. C., Lepping, R. P., Yamamoto, T., and Moretto, T.: Coordinated observations demonstrating external substorm triggering, J. Geophys. Res., 102, 27039-27051, 1997.

Morley, S. K. and Freeman, M. P.: On the association between northward turnings of the interplanetary magnetic field and substorm onsets, Geophys. Res. Lett, 34, L08104, doi:10.1029/ 2006GL028891, 2007.

Rème, H., Bosqued, J.-M., Sauvaud, J.-A., Cros, A., Dandouras, J., Aoustin, C., Bouyssoua, J., Camus, T., Cuvilo, J., Martz, C., MEdale, J. L., Perrier, H., Romefort, D., Rouzaud, J., D’uston, C., Möbius, E., Crocker, K., Granoff, M., Kistler, L. M., Popecki, M., Hovestadt, D., Klecker, B., Paschmann, G., Scholer, M., Carlson, C. W., Curtis, D. W., Lin, R. P., Mcfadden, J. P., Formisano, V., Amata, E., Bavassano-Cattaneo, M. B., Baldetti, P., Belluci, G., Bruno, R., Chionchio, G., Lellis, A. D., Shelley, E. G., Ghielmetti, A. G., Lennartsson, W., Korth, A., Rosenbauer, H., Lundin, R., Olsen, S., Parks, G. K., McCarthy, M., and Balsiger, H.: The Cluster Ion Spectrometry (CIS) Experiment, Space Sci. Rev., 79, 303-350, 1997.

Rème, H., Aoustin, C., Bosqued, J. M., Dandouras, I., Lavraud, B., Sauvaud, J. A., Barthe, A., Bouyssou, J., Camus, Th., CoeurJoly, O., Cros, A., Cuvilo, J., Ducay, F., Garbarowitz, Y., Medale, J. L., Penou, E., Perrier, H., Romefort, D., Rouzaud, J., Vallat, C., Alcayd, D., Jacquey, C., Mazelle, C., d'Uston, C., Möbius, E., Kistler, L. M., Crocker, K., Granoff, M., Mouikis, C., Popecki, M., Vosbury, M., Klecker, B., Hovestadt, D., Kucharek, H., Kuenneth, E., Paschmann, G., Scholer, M., Sckopke, N., Seiden- 
schwang, E., Carlson, C. W., Curtis, D. W., Ingraham, C., Lin, R. P., McFadden, J. P., Parks, G. K., Phan, T., Formisano, V., Amata, E., Bavassano-Cattaneo, M. B., Baldetti, P., Bruno, R., Chionchio, G., Di Lellis, A., Marcucci, M. F., Pallocchia, G., Korth, A., Daly, P. W., Graeve, B., Rosenbauer, H., Vasyliunas, V., McCarthy, M., Wilber, M., Eliasson, L., Lundin, R., Olsen, S., Shelley, E. G., Fuselier, S., Ghielmetti, A. G., Lennartsson, W., Escoubet, C. P., Balsiger, H., Friedel, R., Cao, J.-B., Kovrazhkin, R. A., Papamastorakis, I., Pellat, R., Scudder, J., and Sonnerup, B.: First multispacecraft ion measurements in and near the Earth's magnetosphere with the identical Cluster ion spectrometry (CIS) experiment, Ann. Geophys., 19, 1303-1354, 2001, http://www.ann-geophys.net/19/1303/2001/.

Roelof, E. C. and Sibeck, D. G.: Magnetopause shape as a bivariate function of interplanetary magnetic field $B_{Z}$ and solar wind dynamic pressure, J. Geophys. Res., 98, 21421-21450, 1993.

Rostoker, G., Akasofu, S. I., Baumjohann, W., Kamide, Y., and McPherron, R. L.: The roles of direct input of energy from the solar wind and unloading of stored magnetotail energy in driving magnetospheric substorms, Space Sci. Rev., 46, 93-111, doi:10. 1007/BF00173876, 1987.
Samson, J. C. and Yeung, K. L.: Some genralizations on the method of superposed epoh analysis, Planet. Space Sci., 34, 1133-1142, 1986.

Sandholt, P. E., Farrugia, C. J., Moen, J., and Cowley, S. W. H.: Responses to southward and northward rotations of the interplanetary magnetic field, J. Geophys. Res., 103, 20279-20295, 1998.

Shue, J.-H., Chao, J. K., Fu, H. C., Russell, C. T., Song, P., Khurana, K. K., , and Singer, H. J.: A new functional form to study the solar wind control of the magnetopause size and shape, J. Geophys. Res., 102, 9497-9511, 1997.

Stone, E. C., Frandsen, A. M., Mewaldt, R. A., Christian, E. R., Marglies, D., Ormes, J. F., , and Snow, F.: The Advanced Composition Explorer, Space Sci. Rev., 86, 1-22, 1998.

Weimer, D. R., Ober, D. M., Maynard, N. C., Burke, W. J., Collier, M. R., McComas, D. J., Ness, N. F., and Smith, C. W.: Variable time delays in the propagation of the interplanetary magnetic field, J. Geophys. Res., 107, 1210, doi:10.1029/2001JA009102, 2002. 